\title{
Erratum to: Design for service compatibility
}

\section{Behavioural compatibility checking and diagnosis}

\author{
Georg Grossmann • Michael Schrefl • \\ Markus Stumptner
}

Published online: 11 August 2012

(C) Springer-Verlag 2012

\section{Erratum to: Softw Syst Model}

\section{DOI 10.1007/s10270-012-0229-0}

Unfortunately, the original article has been published with errors that are corrected below.

The correct version of Fig. 14 should be:

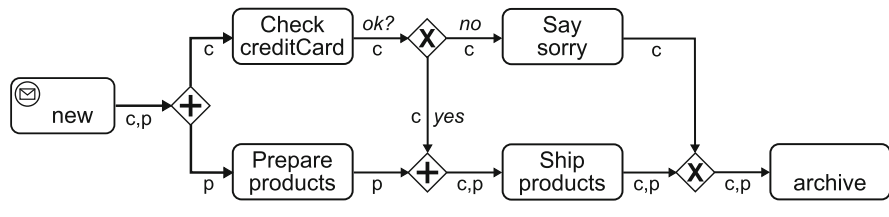

(a)

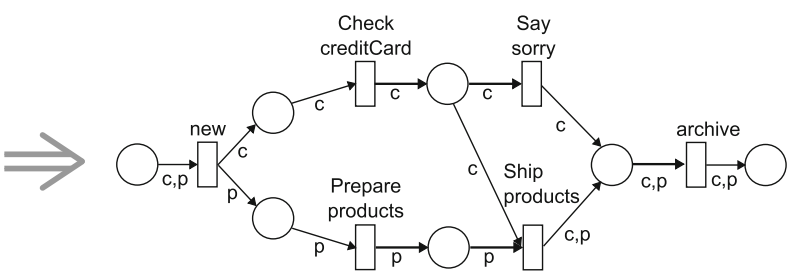

(b)

Fig. 14 BPMN with sequence flow labels and corresponding labelled behaviour diagram

The correct Fig. 14b shows the poststates of "Say sorry" and "Ship products" as a single state.

The corrected text in Example 17 should read:

Consequently, AccLog[Buyer]*XBuyer becomes a noninvocation consistent extension to AccLog[Buyer] and behaviour service compatibility is no longer given:

The online version of the original article can be found under doi:10.1007/s10270-012-0229-0.

G. Grossmann ( $\varangle) \cdot$ M. Schrefl · M. Stumptner

School of Computer and Information Science,

University of South Australia, Adelaide, Australia

e-mail: georg.grossmann@cs.unisa.edu.au 